\title{
Effect of transition from sitaxsentan to ambrisentan in pulmonary arterial hypertension
}

\author{
This article was published in the following Dove Press journal: \\ Vascular Health and Risk Management \\ 3 March 20II \\ Number of times this article has been viewed
}

\section{Zeenat Safdar}

Division of Pulmonary-Critical Care Medicine, Baylor College of Medicine, Houston, Texas, USA
Correspondence: Zeenat Safdar Assistant Professor of Medicine, Pulmonary-Critical Care Medicine, Baylor College of Medicine, Houston, TX, USA

Tel + I 7/37982400

Email safdar@bcm.edu
Introduction: Currently available endothelin receptor antagonists for treating pulmonary arterial hypertension block either the endothelin (ET) receptor A or both A and B receptors. Transition from one endothelin receptor antagonist to another may theoretically alter side-effects or efficacy. We report our experience of a transition from sitaxsentan to ambrisentan, both predominant $\mathrm{ET}_{\mathrm{A}}$ receptor antagonists, in pulmonary arterial hypertension patients.

Methods: At Baylor Pulmonary Hypertension Center, 18 patients enrolled in the open-label extension phase of the original sitaxsentan studies (Sitaxsentan To Relieve ImpaireD Exercise) were transitioned to ambrisentan (from July 2007 to September 2007) at the time of study closure. Pre-transition (PreT), 1 month (1Mth) and 1 year (1Yr) post-transition assessments of 6-minute walk distance (6MWD), brain naturetic peptide (BNP) levels, WHO functional class (WHO FC), Borg dyspnea score (BDS), oxygen saturation, liver function, and peripheral edema were compared.

Results: 6MWD was $356 \pm 126 \mathrm{~m}$ at PreT, $361 \pm 125 \mathrm{~m}$ at $1 \mathrm{Mth}$, and $394 \pm 114 \mathrm{~m}$ at $1 \mathrm{Yr}$ (mean $\pm \mathrm{SD}$ ). There was no difference in the walk distance at $1 \mathrm{Mth}$ and 1 Yr post transition compared with PreT ( $P=0.92,0.41$ respectively). Oxygen saturation was no different at $1 \mathrm{Mth}$ and $1 Y r$ to PreT level $(P=0.49$ and $P=0.06$ respectively). BNP was $178 \pm 244 \mathrm{pg} / \mathrm{mL}$ at PreT, $129 \pm 144 \mathrm{pg} / \mathrm{mL}$ at $1 \mathrm{Mth}$ and $157 \pm 201$ at 1 Yr. Peripheral edema was present in $7 / 18$ patients at PreT, in $8 / 16$ patients at $1 \mathrm{Mth}$, and in $6 / 13$ patients at $1 \mathrm{Yr}$ post transition. Proportions of patients with edema over these 3 time points did not change significantly $(P=0.803)$. At $1 Y r$, 2 patients had died, 1 had undergone lung transplantation, 1 had relocated, and 1 patient was started on intravenous prostacyclin therapy. Over 3 points (baseline, 1 month, and 1 year), there was no significant change in function class $(P=0.672)$

Conclusion: Our limited data suggest that $\mathrm{ET}_{\mathrm{A}}$ receptor antagonists can be switched from one to another with sustained exercise capacity and maintained WHO FC with no increase in incidence of peripheral edema.

Keywords: right heart failure, 6-minute walk distance, endothelial receptor antagonist, echocardiogram

\section{Introduction}

Pulmonary arterial hypertension (PAH) is a progressive disease resulting from pulmonary vascular remodeling leading to right heart failure. ${ }^{1}$ Endothelin 1 (ET-1), a modulator of pulmonary vascular remodeling, has an important role in the pathophysiology of this disease. ET-1 binds to 2 receptors, $\mathrm{ET}_{\mathrm{A}}$ and $\mathrm{ET}_{\mathrm{B}}$. Endothelin receptor antagonists (ETRAs) block either A or A and B receptors are used to treat PAH. Two Food and Drug Administration (FDA) -approved ETRAs are available to treat $\mathrm{PAH}$ in the US. Sitaxsentan, a predominantly $\mathrm{ET}_{\mathrm{A}}$ receptor antagonist, was studied 
in the US, Europe, and Canada; sitaxsentan was approved in Europe and Canada but did not receive FDA approval in the US. Thus patients enrolled in open label sitaxsentan extension studies were transitioned to ambrisentan at the time of sitaxsentan study closure. We report our singlecenter experience of patients transitioning from sitaxsentan to ambrisentan after study closure.

To date indications for changing from one ETRA to another ETRA are anecdotal. Side effect profiles such as liver toxicity and drug interactions differ between these ETRAs. ${ }^{2}$ Due to the predominant blockade of endothelin A receptor with sitaxsentan we decided to switch our patients from sitaxsentan to ambrisentan (both predominantly $\mathrm{ET}_{\mathrm{A}}$ receptor antagonists). We present the available long-term clinical data for 18 patients switched to ambrisentan at the time of sitaxsentan study closure.

\section{Method}

Eighteen PAH patients were enrolled in the open-label extension phase of the original sitaxsentan studies (Sitaxsentan To Relieve ImpaireD Exercise [STRIDE] -2, -3 and -6) at Baylor Pulmonary Hypertension Center. All patients were on $100 \mathrm{mg}$ oral daily of sitaxsentan. Patients were enrolled in the open label extension phase of clinical studies, which permitted addition of other PAH medications as clinically indicated. These patients were changed to ambrisentan (5 mg oral daily) (between July 2007 and September 2007) at the time of study closure. This transition was necessary because sitaxsentan did not gain FDA approval in US and hence this drug was unavailable to patients after sitaxsentan study was closed.

Data was collected for each patient at pre-transition (PreT), 1 month (1Mth) (48 \pm 28 days, range 19-123), and 1 year (1Yr) post transition (401 \pm 73 days, range 252-489). Collected data included 6-minute walk distance (6MWD), brain naturetic peptide (BNP) plasma concentrations, WHO functional class (WHO FC), Borg dyspnea score (BDS), presence of peripheral edema, changes in diuretic dose, and liver function tests. Patient 2 was hospitalized at the time of transition for acute gastroenteritis and remained in the hospital till he died from worsening right heart failure. Hence limited data were available for patient 2 . Patient 17 had only laboratory testing done at $1 \mathrm{Mth}$ and was unable to do the walk test at 1 Yr due to severe hip pain. Patient 3 was taken off ambrisentan and started on intravenous treprostinil due to worsening pulmonary hypertension 9 month post transition and died 13 months post transition. This patient did not have a walk test done at 1Yr because of severe back pain, which was considered a treprostinil related side-effect by the treating physician. Patient 18 progressed to WHO FC IV at $1 \mathrm{Mth}$ from WHO FC III at baseline and subsequently underwent lung transplantation 5.5 months post transition. Patient 9 relocated 5 months post transition. Hence, 1 Yr data available for 13 patients was included in this analysis.

\section{Statistical analysis}

All data are reported as mean \pm standard deviation (SD) unless stated otherwise. Differences between groups were determined by using paired Student's $t$-test. A chi-square test was used to evaluate the significance of change of WHO FC over 3 time points. We also used a chi-square test to examine the difference in proportions of patients who experienced edema at 3 time points. Analyses were conducted using SAS (v. 9.2;SAS Institute Inc., Cary, NC). Significance was accepted at $P<0.05$ and all hypothesis testing was two-sided.

\section{Results}

Demographic and baseline characteristics are outlined in Table 1. There were 15 females and 3 males with a mean age of $52 \pm 14$ (mean \pm SD). At $1 \mathrm{Mth}$, the ambrisentan dose was increased in 7 patients to $10 \mathrm{mg}$ and 10 patients were continued on $5 \mathrm{mg}$ dose. Patient 2 was on ambrisentan $5 \mathrm{mg}$ when he died in the hospital. At $1 \mathrm{Yr}, 8$ patients were on $10 \mathrm{mg}$ dose, 5 patients remained on $5 \mathrm{mg}$, and 1 patient was taken off ambrisentan for worsening disease and started on intravenous prostacyclin therapy (patient 3). Patient 11 had sildenafil added to ambrisentan 4 months prior to 1 Yr. None of the patients discontinued ambrisentan due to liver function abnormalities (Table 2). Patient 15 had increased aspartate aminotransferase at $1 \mathrm{Mth}(3.5 \times$ upper limit of normal $)$ which returned to normal on repeat testing in 1 week without interruption in therapy.

$6 \mathrm{MWD}$ was $356 \pm 126 \mathrm{~m}$ at PreT, $361 \pm 125 \mathrm{~m}$ at $1 \mathrm{Mth}$, and $394 \pm 114 \mathrm{~m}$ at 1 Yr. There was no difference in the $6 \mathrm{MWD}$ at $1 \mathrm{Mth}$ and at $1 \mathrm{Yr}$ compared with PreT $(P=0.92$ and $P=0.41$ respectively) (Figure 1 ). BNP was not significantly different at $1 \mathrm{Mth}$ and at $1 \mathrm{Yr}$ compared with PreT $(P=0.50$ and $P=0.83$ respectively) (Figure 2 ). BDS was $2.5 \pm 1.2$ (range 0 to 4 ) at PreT in 17 patients, $2.4 \pm 1.4$ (range 0 to 4 ) at $1 \mathrm{Mth}$ in 16 patients and $2.6 \pm 1.3$ (range 0.5 to 5 ) at $1 \mathrm{Yr}$ in 12 patients (Figure 3 ). These values was not significantly different ( $P=0.88$ and 0.81 respectively).

Eleven of the 18 patients were idiopathic PAH (IPAH) patients. Patients were divided into 2 groups - IPAH, and PAH associated with other conditions, and data was analyzed to 
Table I Demographics and baseline patient characteristics of transitioned patients

\begin{tabular}{|c|c|c|c|c|c|c|c|}
\hline $\begin{array}{l}\text { Patient } \\
\text { number }\end{array}$ & Age, yr & Gender & Race & BMI, kg/m² & PAH etiology & PAH medications* & $\begin{array}{l}\text { Duration of illness } \\
\text { at transition, yrs }\end{array}$ \\
\hline $\mathrm{I}$ & 50 & $\mathrm{~F}$ & C & 19.31 & IPAH & None & 6.3 \\
\hline 2 & 44 & M & C & 21.89 & $\mathrm{CHD}$ associated $\mathrm{PAH}$ & Treprostinil, sildenafil & 5.4 \\
\hline 3 & 72 & $M$ & C & 20.48 & IPAH & Iloprost, sildenafil & 3.9 \\
\hline 4 & 54 & $\mathrm{~F}$ & C & 28.03 & CTD associated PAH & Sildenafil & 4.3 \\
\hline 5 & 42 & $\mathrm{~F}$ & C & 34.37 & $\mathrm{IPAH}$ & Sildenafil & 7.9 \\
\hline 6 & 60 & $\mathrm{~F}$ & $\mathrm{H}$ & 25.24 & IPAH & Sildenafil & 7.4 \\
\hline 7 & 53 & $\mathrm{~F}$ & C & 36.39 & IPAH & Sildenafil & 3.6 \\
\hline 8 & 32 & $M$ & C & 43.45 & IPAH & Sildenafil, iloprost & 3.3 \\
\hline 9 & 33 & $\mathrm{~F}$ & Asian & 21.4 & $\mathrm{CHD}$ associated $\mathrm{PAH}$ & Iloprost & 4.8 \\
\hline 10 & 49 & $\mathrm{~F}$ & $\mathrm{C}$ & 26.73 & CTD associated PAH & Sildenafil & 3.8 \\
\hline 11 & 56 & $\mathrm{~F}$ & $\mathrm{H}$ & 31.17 & $\mathrm{IPAH}$ & None & 3.0 \\
\hline 12 & 68 & $\mathrm{~F}$ & $\mathrm{H}$ & 31.95 & IPAH & Sildenafil & 3.4 \\
\hline 13 & 59 & $\mathrm{~F}$ & C & 24.58 & CTD associated PAH & None & 7.2 \\
\hline 14 & 67 & $\mathrm{~F}$ & Asian & 23.04 & IPAH & Sildenafil, Iloprost & 4.6 \\
\hline 15 & 45 & $\mathrm{~F}$ & Asian & 25.56 & $\mathrm{CHD}$ associated $\mathrm{PAH}$ & None & 37 \\
\hline 16 & 25 & $\mathrm{~F}$ & C & 24.85 & $\mathrm{IPAH}$ & Sildenafil & 1.2 \\
\hline 17 & 73 & $\mathrm{~F}$ & C & 25.68 & IPAH & Sildenafil & 6.8 \\
\hline 18 & 61 & $\mathrm{~F}$ & C & 23.4 & IPAH & Epoprostenol & 7.7 \\
\hline
\end{tabular}

Note: *In addition to sitaxsentan.

Abbreviations: PAH, pulmonary arterial hypertension; IPAH, idiopathic pulmonary arterial hypertension; CTD, collagen tissue disease; CHD, congenital heart disease; C, Caucasian; H, Hispanic; BMI, body mass index.

determine whether our findings would differ in patients with different PAH etiologies. There was no significant difference between the 2 groups at PreT, 1Mth, and $1 \mathrm{Yr}$ in 6MWD ( $P=0.42,0.34,0.27$ respectively), BNP levels $(P=0.63$, $0.90,0.55$ respectively), oxygen saturation $(P=0.35,0.47$, 0.06 respectively), and $\operatorname{BDS}(0.55,0.45,0.39$ respectively).

Peripheral edema was present in $7 / 18$ patients at PreT, $8 / 16$ patients at $1 \mathrm{Mth}$, and in $6 / 13$ patients at $1 \mathrm{yr}$ (Figure 3 ). At $1 \mathrm{Mth}$, the diuretic dose was increased in 2 of the 16 patients (patients 4 and 18). At 1Yr, a second diuretic was added for patient 4 . Proportions of patients with edema over these 3 time points did not change significantly $(P=0.803)$.

Oxygen saturation was not different at $1 \mathrm{Mth}$ compared with PreT $(P=0.49)$. Oxygen requirements remained unchanged except for 1 patient who was on room air PreT and was started on $2 \mathrm{~L}$ oxygen at $1 \mathrm{Mth}$ and remained on $2 \mathrm{~L}$ at $1 \mathrm{Yr}$. $1 \mathrm{Yr}$ data

Table 2 Serum aminotransferase concentrations in transitioned patients

\begin{tabular}{llll}
\hline & $\begin{array}{l}\text { Pre } \\
\text { transition }\end{array}$ & $\begin{array}{l}\text { I month post } \\
\text { transition }\end{array}$ & $\begin{array}{l}\text { I year post } \\
\text { transition }\end{array}$ \\
\hline AST $(\mathrm{mU} / \mathrm{mL})$ & $19 \pm 8$ & $31 \pm 35^{*}$ & $26 \pm 19$ \\
ALT $(\mathrm{mU} / \mathrm{mL})$ & $16 \pm 7$ & $23 \pm 23$ & $24 \pm 18$ \\
\hline
\end{tabular}

Notes: *Patient 15 AST increased to $151 \mathrm{mU} / \mathrm{mL}$ at 1 month then decreased to $19 \mathrm{mU} / \mathrm{mL}$ in I week without any intervention. This patient was subsequently switched to bosentan (3 months post transition) for worsening right heart failure and died 5 months after transition. Normal laboratory values: AST = $10-42 \mathrm{mU} / \mathrm{mL}$; $\mathrm{ALT}=10-60 \mathrm{mU} / \mathrm{mL}$.

Abbreviations: AST, aspartate aminotransferase; ALT, alanine transaminase. were available for 13 patients and oxygen saturation slightly improved compared with PreT $(P=0.06)$.

Over 3 points (PreT, $1 \mathrm{Mth}$, and $1 \mathrm{Yr}$ ), there was no significant change in WHO function class $(P=0.672)$ (Figure 4$)$.

\section{Discussion}

In this single-center retrospective study switching from sitaxsentan to ambrisentan was safe and efficacy was maintained. At the end of the open label extension phase of STRIDE studies, we switched all of the patients then enrolled to ambrisentan. In the open label extension phase, addition of PAH therapies was allowed. Prior to transitioning, 3 patients enrolled in this extension phase had died. Our data suggest that switching from a selective ETRA to another selective ETRA may be reasonable and safe. However, 3 patients in our cohort developed disease worsening and 2 patients died

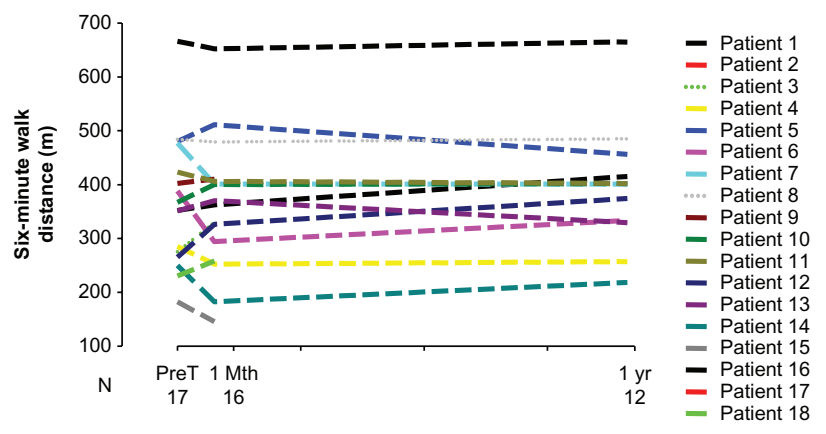

Figure I Six-minute walk distance at transition and follow-up in $\mathrm{PAH}$ patients. Abbreviation: PAH, pulmonary hypertension. 


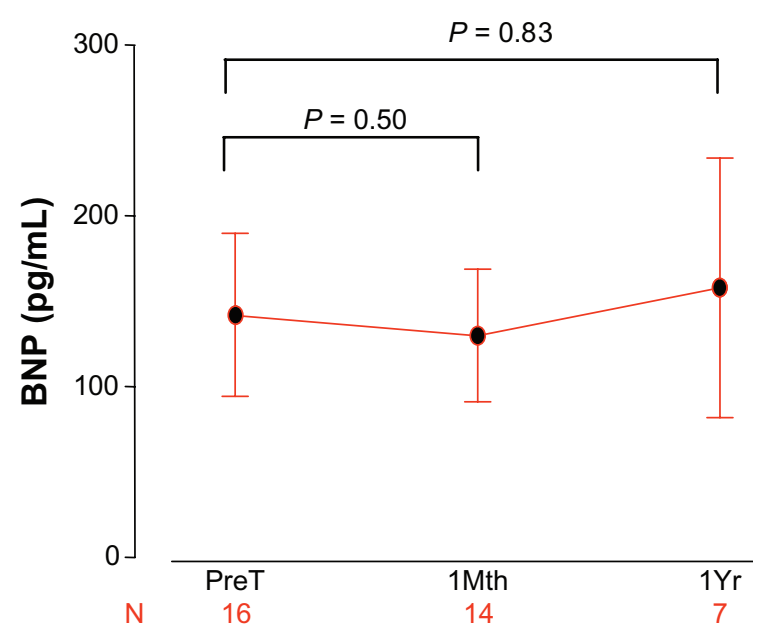

Figure 2 BNP levels at transition and follow-up in PAH patients. Data presented as mean \pm standard error.

Abbreviations: BNP, brain naturetic peptide; PAH, pulmonary hypertension.

after this change, suggesting that individual responses to selective ET receptor antagonists may vary.

Ambrisentan and sitaxsentan are both $\mathrm{ET}_{\mathrm{A}}$-selective antagonists. Based on in vitro competitive receptor binding assay, ambrisentan has a 77 -fold affinity for $\mathrm{ET}_{\mathrm{A}}$ compared with $\mathrm{ET}_{\mathrm{B}}$ receptors. ${ }^{3}$ On the other hand, sitaxsentan has a $\sim 6500$-fold affinity for $\mathrm{ET}_{\mathrm{A}}$ compared with $\mathrm{ET}_{\mathrm{B}}$ receptors. ${ }^{4,5}$ Activation of the $\mathrm{ET}_{\mathrm{A}}$ receptor on smooth muscle cells causes sustained vasoconstriction and proliferation of these cells. However, activation of $\mathrm{ET}_{\mathrm{B}}$ on endothelial cells

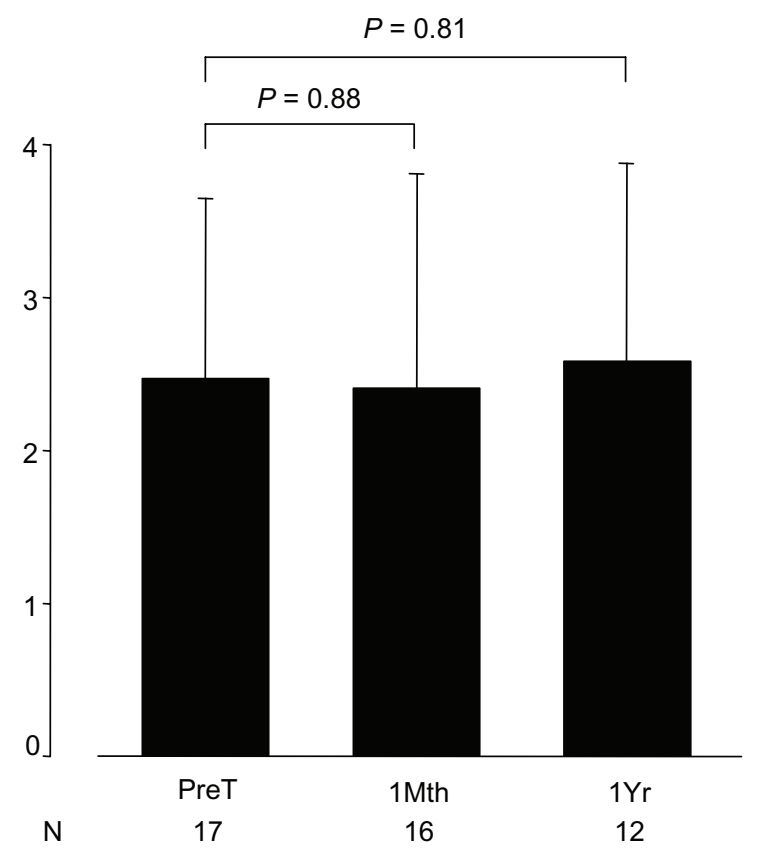

Figure 3 Borg dyspnea score at transition and follow-up in PAH patients. Data presented as mean \pm standard deviation.

Abbreviations: $\mathrm{PAH}$, pulmonary hypertension; SD, standard deviation.

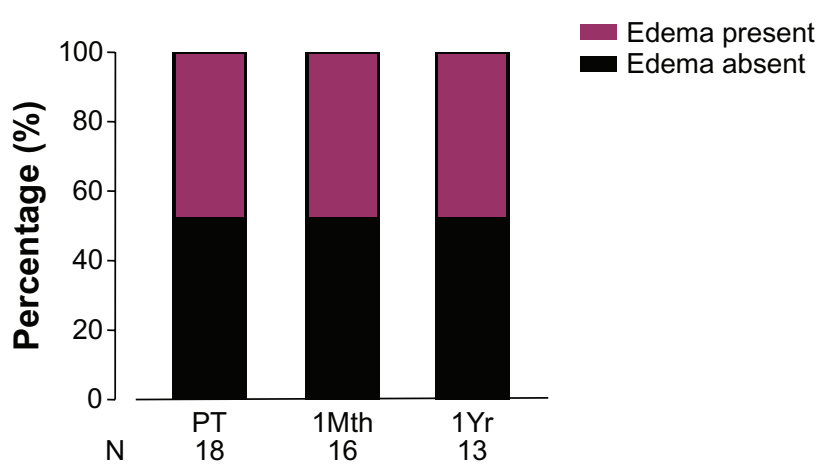

Figure 4 Presence of peripheral edema at transition and follow-up. Data presented as percentage (\%). One patient had undergone lung transplantation, I patient had relocated, and 2 patients had died at I year follow-up.

induces clearance of ET-1 from the circulation and mediates vasodilation through the activation of $\mathrm{NO}$ and prostacyclin. This selectivity of $\mathrm{ET}_{\mathrm{A}}$ receptor blockages has been proposed to prevent the deleterious effects of $\mathrm{ET}_{\mathrm{A}}$, while allowing the favorable effects of $\mathrm{ET}_{\mathrm{B}}{ }^{2}$ However, this difference in selectively has not translated into substantial differences in clinical efficacy, as shown by the published clinical studies. ${ }^{6-10}$ Our data show that the walk distance was maintained for up to 1 year after the switch in the ETRA. This suggests that selective ETRA can be used interchangeably as required by the clinical necessity. However, we caution against using this data for the dual receptor ETRA, because we switched our patients to a selective ETRA, ambrisentan, in our cohort.

Both ambrisentan and sitaxsentan have a long half-life and require once daily dosing. ${ }^{7,11,12}$ Ambrisentan is a propanoic acid-based compound that is metabolized predominately by glucuronidation and transported via the bile. Sitaxsentan is derived from amidothiophenesulponamides by a series of chemical modifications. It is metabolized by the CYP2CP and CYP3A4 with $50 \%$ to $60 \%$ of the dose excreted in the urine and the remaining in feces. The incidence of liver function

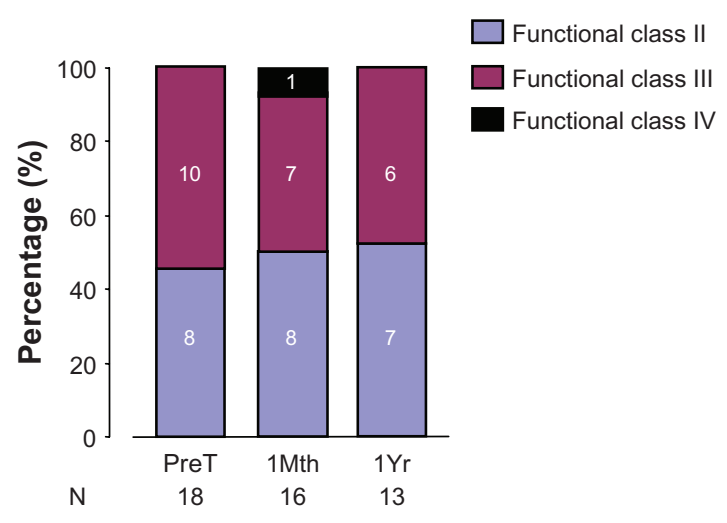

Figure 5 WHO Functional Class at transition and at follow-up in transitioned patients. Data presented as percentage (\%). 
test abnormalities is similar between the two drugs (3\% with both ambrisentan and sitaxsentan). ${ }^{7,11,13}$

Transitioning from one ETRA to another ETRA may be required in different clinical situations. This may be because of side-effects, liver function abnormalities, or availability of the drug. McGoon et al have previously shown that patients who discontinued bosentan due to liver function test abnormalities tolerated ambrisentan and this change resulted in improvement in walk distance. ${ }^{14}$ We have previously shown that carefully selected patients can be safely transitioned from intravenous prostacyclin to oral agents. ${ }^{15}$ Our data was obtained from patients with normal liver function who were switched to ambrisentan when the sitaxsentan did not gain FDA approval in US. We included patients who died, were lost to follow-up, or underwent lung transplantation. We did not exclude any patient to prevent an introduction of bias in data collection. Patient 15 in our cohort developed transient elevation in transaminase, which resolved spontaneously without any medical intervention. This patient had a congenital heart defect (ventricular septal defect), Eisenmenger physiology, and Down syndrome. This patient was not on any additional PAH therapy due to significant underlying medical conditions and parents' request. This patient did not develop increased edema at $1 \mathrm{Mth}$ and the parents felt that the breathing was unchanged. However, this patient developed an intolerable cough and 3 months post transition the walk distance had significantly deteriorated and therefore the patient was switched to bosentan and subsequently died 5 months post transition. It is conceivable that the clinical condition may have deteriorated when this patient was switched from sitaxsentan to ambrisentan. On the other hand, this patient was 45 years of age at the time of transition and had been diagnosed with PAH for the previous 37 years. Possibly this patient was at the end of the disease spectrum.

Peripheral edema is considered to be a class side-effect of ETRAs, ${ }^{16}$ with a greater percentage of older patients (>65 years) experiencing higher rates of peripheral edema. ${ }^{16}$ Some ETRAs were thought to be associated with more peripheral edema than others. However, our data suggest that at least in the selective ETRAs there was no significant worsening of peripheral edema. None of the patients required intravenous diuresis or hospitalization for worsening edema. One patient, however, who was already in the hospital at the time of study closure, developed worsening right heart failure and subsequently died. This could have been related to the progression of disease or, on the other hand, may have been related to worsening right heart failure as a consequence of increased fluid retention caused by a switch in the ETRA.
Therefore, switching ETRA in patients with marginal clinical status should be undertaken cautiously. We do not recommend switching between ETRAs without a compelling reason such as when side-effects must be mitigated. Hence, such switches should be undertaken only when they confer a greater clinical benefit to the patient.

\section{Acknowledgments}

This study was supported by the National Institute of Health grant K23HL-093214 to ZS. Part of this study was presented at the European Respiratory Society Meeting, Barcelona 2010, and at the American Thoracic Society Meeting, New Orleans 2010 as an abstract.

The author thanks Degang Wang, PhD for his assistance in the statistical analysis, and Helena Purl, RN, and Ms Janice Brister for their help in preparing this manuscript.

\section{Disclosure}

ZS has been on Gilead Science, Actelion, United Therapeutics and Pfizer advisory boards and has provided consultancy for these companies.

\section{References}

1. Rubin LJ. Pathology and pathophysiology of primary pulmonary hypertension. Am J Cardiol. 1995;75(3):51A-54A.

2. Safdar Z. Targeted oral therapies in the treatment of pulmonary arterial hypertension. Clin Drug Investig. 2010;30(12):811-826.

3. Valerio CJ, Kabunga P, Coghlan JG. Safety and efficacy of ambrisentan in the treatment of pulmonary arterial hypertension. Clin Med Ther. $2009 ; 1: 541-556$.

4. Wu C, Chan MF, Stavros F, et al. Discovery of TBC11251, a potent, long acting, orally active endothelin receptor-A selective antagonist. J Med Chem. 1997;40(11):1690-1697.

5. Wu C, Decker ER, Blok N, et al. Endothelin antagonists: substituted mesitylcarboxamides with high potency and selectivity for ET(A) receptors. J Med Chem. 1999;42(22):4485-4499.

6. Opitz CF, Ewert R, Kirch W, Pittrow D. Inhibition of endothelin receptors in the treatment of pulmonary arterial hypertension: does selectivity matter? Eur Heart J. 2008;29(16):1936-1948.

7. Galie N, Badesch D, Oudiz R, et al. Ambrisentan therapy for pulmonary arterial hypertension. J Am Coll Cardiol. 2005;46(3):529-535.

8. Oudiz RJ, Torres F, Frost AE, et al. ARIES-1: A placebo-controlled, efficacy and safety study of ambrisentan in patients with pulmonary arterial hypertension. Chest. 2006;130(4):121S-a-.

9. Galie N, Olschewski H, Oudiz RJ, et al. Ambrisentan for the treatment of pulmonary arterial hypertension: results of the ambrisentan in pulmonary arterial hypertension, randomized, double-blind, placebocontrolled, multicenter, efficacy (ARIES) study 1 and 2. Circulation. 2008;117(23):3010-3019.

10. Rubin LJ, Badesch DB, Barst RJ, et al. Bosentan therapy for pulmonary arterial hypertension. N Engl J Med. 2002;346(12): 896-903.

11. Barst RJ, Langleben D, Frost A, et al. Sitaxsentan therapy for pulmonary arterial hypertension. Am J Respir Crit Care Med. 2004; 169(4):441-447.

12. Motte S, McEntee K, Naeije R. Endothelin receptor antagonists. Pharmacol Ther. 2006;110(3):386-414. 
13. Langleben D, Cacoub P. A review of STRIDE-2 and STRIDE-2X: the case for selective endothelin receptor blockade. Eur J Clin Invest. 2009; 39 Suppl 2:27-31.

14. McGoon MD, Frost AE, Oudiz RJ, et al. Ambrisentan therapy in patients with pulmonary arterial hypertension who discontinued bosentan or sitaxsentan due to liver function test abnormalities. Chest. 2009; 135(1):122-129.
15. Safdar Z. Outcome of pulmonary hypertension subjects transitioned from intravenous prostacyclin to oral bosentan. Respir Med. 2009; 103(11):1688-1692.

16. Kingman M, Ruggiero R, Torres F. Ambrisentan, an endothelin receptor type A-selective endothelin receptor antagonist, for the treatment of pulmonary arterial hypertension. Expert Opin Pharmacother. 2009; 10(11):1847-1858.

\section{Publish your work in this journal}

Vascular Health and Risk Management is an international, peerreviewed journal of therapeutics and risk management, focusing on concise rapid reporting of clinical studies on the processes involved in the maintenance of vascular health; the monitoring, prevention and treatment of vascular disease and its sequelae; and the involvement of metabolic disorders, particularly diabetes. This journal is indexed on PubMed Central and MedLine. The manuscript management system is completely online and includes a very quick and fair peer-review system, which is all easy to use. Visit http://www.dovepress.com/ testimonials.php to read real quotes from published authors.

Submit your manuscript here: http://www.dovepress.com/vascular-health-and-risk-management-journal 